\title{
A HYBRID TDM/WDM-PON SYSTEM WITH FWM-GENERATED SOURCE OF MULTIWAVELENGTH OPTICAL SIGNALS
}

\author{
I. Lyashuk, A. Shchemelev, G. Ivanov \\ Institute of Telecommunications, Riga Technical University, \\ 12 Āzenes Str., Rīga, LV-1048, LATVIA
}

\begin{abstract}
A new approach to FTTx solutions is proposed, in the framework of which a hybrid TDM/WDM system using cascaded FWM-generated optical signals is evaluated by calculating the BER parameter and the optical power budget. Computer simulation is employed as the main method of calculations, with the results presented both in numerical and graphical forms. The results show that the use of a forward error correction allows the power margin of $4 \mathrm{~dB}$ to be achieved for the system to work reliably. The system can provide the total number of users up to 128 $(8 \lambda \times 16$ TDM users) with a bandwidth of multiple hundreds of Mbit/s p.u. by means of the existing passive optical networking infrastructure, with only minor improvements needed.

Key words: Wavelength Division Multiplexing-Passive Optical Networks (WDM-PON), Four-Wave Mixing (FWM), Fiber Optic Parametric Amplifier (FOPA).
\end{abstract}

\section{INTRODUCTION}

The evolution of FTTx (fiber-to-the-home, -building, -curb, etc.) broadband network architecture has led to the development of a number of optical network access technologies, two most popular being the ITU-T (International Telecommunication Union - Telecommunication sector) standardized $2.4 \mathrm{Gbit} / \mathrm{s}$ GPON (Gigabit Passive Optical Network) and the IEEE (Institute of Electrical and Electronics Engineers) $1 \mathrm{Gbit} / \mathrm{s}$ EPON (Ethernet PON) [1]. Until recently, these technologies met the requirements of telecommunication service providers in terms of per user (p. u.) bandwidth. However, the new generation of telecommunication services, like the triple play, HDTV (High Definition Television), and 3D video, increased the bandwidth demand of a downstream channel to the order of hundreds of Mbit/s p. u. - the number unreachable for the existing access technologies. It is also obvious that the conventional TDM (Time Division Multiplexing) solutions allow achievement of such a bandwidth only by increasing the bit rate of a common channel to $40 \mathrm{Gbit} / \mathrm{s}$. As a result, this will lead to an inadequate complexity of user equipment. The alternative high-speed FTTx solution employs the WDM (Wavelength Division Multiplexing)-PON technology [2].

The WDM-PON solutions can be divided into two major groups: the first one uses an already installed cable plant, with AWG (Arrayed Waveguide Grating) optical multiplexers to be added to the network. The second group requires new physical and logical topologies [1]. While the first group is economically more efficient, the second allows a higher scalability and a greater $\mathrm{p}$. u. bandwidth to be achieved [1,2]. In view of the cost efficiency of the solution, a new Hybrid TDM/WDM-PON technological approach is proposed, the main advantage of 
which over its competitors is the use of the existing cable plant, while the overall bandwidth of the system increases considerably [2].

The proposed Hybrid TDM/WDM-PON solution, which is based on the key idea of TDM-PON systems with OLT (Optical Line Terminal) and ONU (Optical Network Unit), consists in adding the multiple wavelength division multiplexed channels (Fig. 1) to increase the overall bandwidth. The total number of wavelengths in the proposed system is 8 , but it can potentially be raised up to 16 using a different multiwavelength source. The 8-channel system was chosen due to a convenient downstream/upstream bit rate ratio 8/1 (10 Gbit/s Down/ $1.25 \mathrm{Gbit} / \mathrm{s}$ Up; for a 128-channel system this ratio is, respectively, 625/78 Mbit/s). The number of users is 16 per wavelength and is limited by the optical power budget. A common $10 \mathrm{Gbit} / \mathrm{s}$ channel at $1.3 \mu \mathrm{m}$ wavelength is used for the upstream flow which necessitates a high-speed optical burst receiver. Currently, the performance of optical burst receivers has already reached $10 \mathrm{Gbit} / \mathrm{s}$ in laboratory conditions [3].

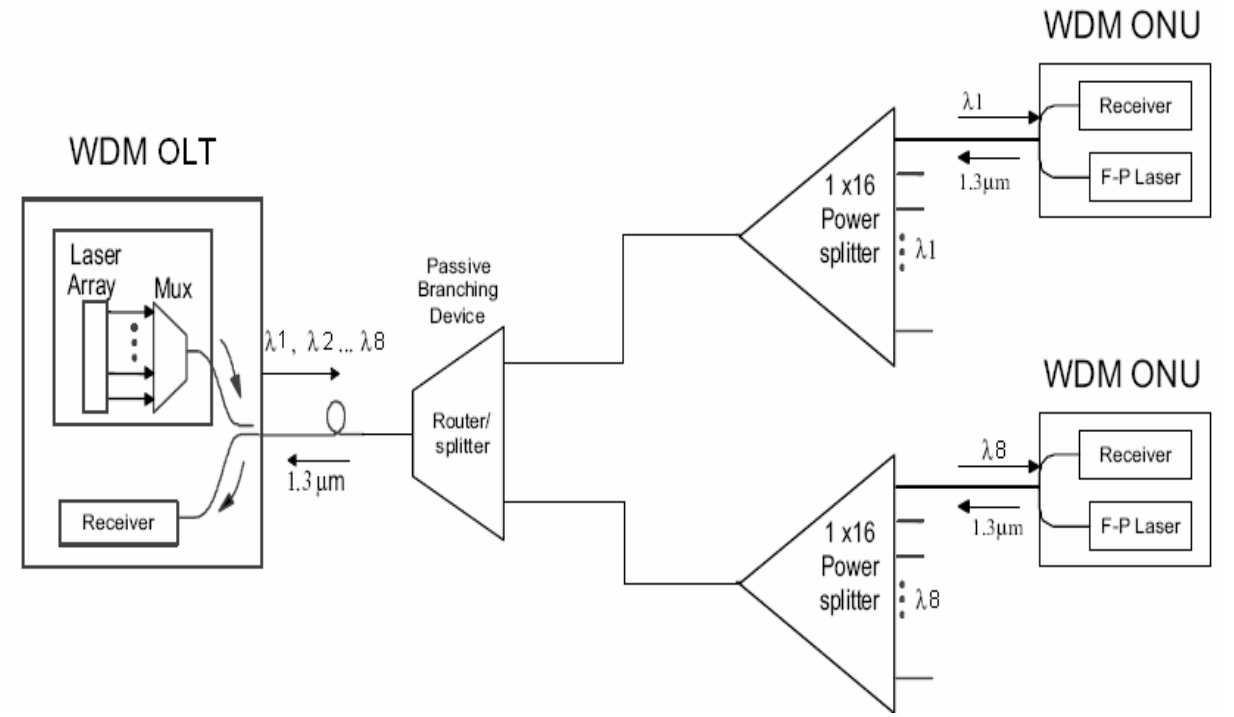

Fig. 1. Hybrid TDM/WDM-PON system.

A laser array seems to be an obvious choice; we however propose generation of multiwavelength optical signals by four-wave mixing (FWM) in a highly nonlinear media - HNLF (Highly Nonlinear Fiber). Our solution has a number of advantages as compared with the laser arrays: first, only two lasers are needed instead of eight; second, in the case of a laser failure the proposed array of 2 lasers is easier to replace. The disadvantages are: the need for high-powered lasers and for accurate tuning of the nonlinear media.

The main objectives of our research could be listed as follows.

- To optimize the pumping lasers' power and nonlinear fiber length thus minimizing the power non-uniformity of FWM-generated optical carrier frequencies; to find the conditions for carrier frequency equivalence to the ITU-T DWDM frequency grid.

- To perform the power margin calculation for the worst (as to the power level) downlink/downstream optical carrier frequency (one of the eight lambdas) generated by four-wave mixing. 
- To perform the power margin calculation for the upstream channel with a semiconductor optical amplifier (SOA).

- To evaluate the possible splitting ratio as well as the maximum achievable number of users for this solution.

\section{GENERATION OF MULTIWAVELENGTH OPTICAL SIGNAL USING FOUR-WAVE MIXING IN HIGHLY NONLINEAR MEDIA}

The nonlinear optical four-wave mixing (FWM) process has many applications in today's optical telecommunication systems, one of them being the generation of a multiwavelength optical source with cascaded FWM products. The phenomenon of such a mixing is described in a series of papers by Arismar Cerqueira S. Jr. et al [4-7]. A multiwavelength optical source based on this approach (for its spectrum see Fig. 2) is also mentioned in these papers, though its possible applications in telecommunication systems have not yet been properly studied.

a)

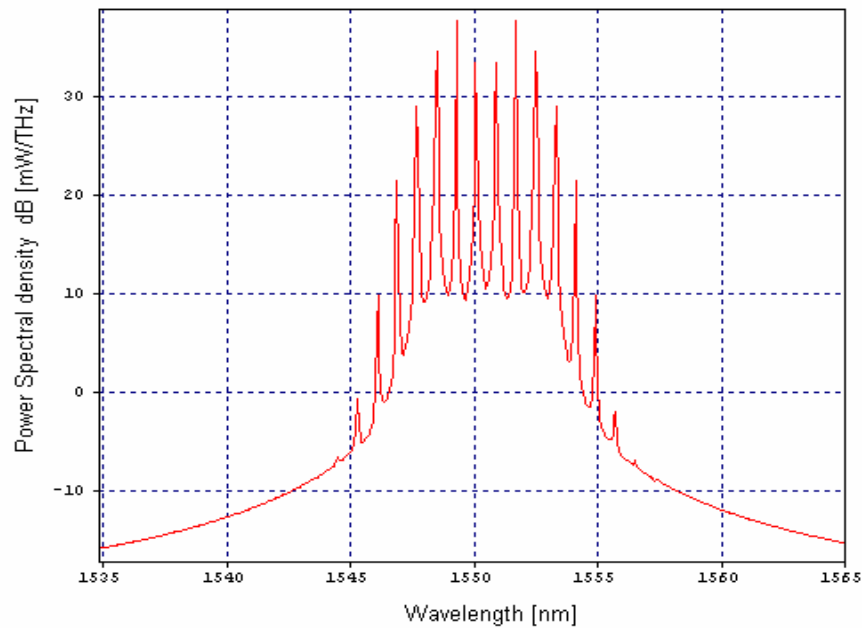

b)

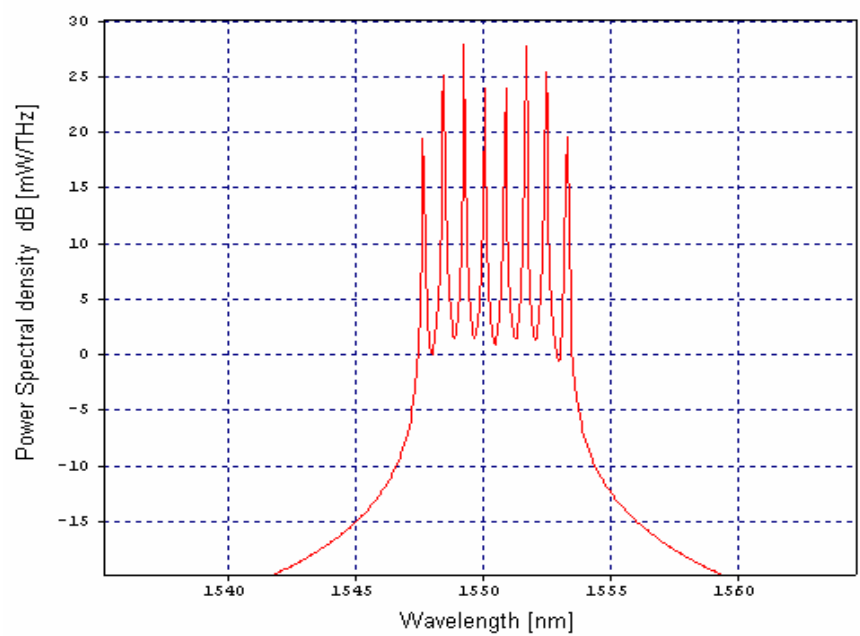

Fig. 2. Cascaded FWM signal:

before $(a)$ and after $(b)$ filtering and modulation. 
a)
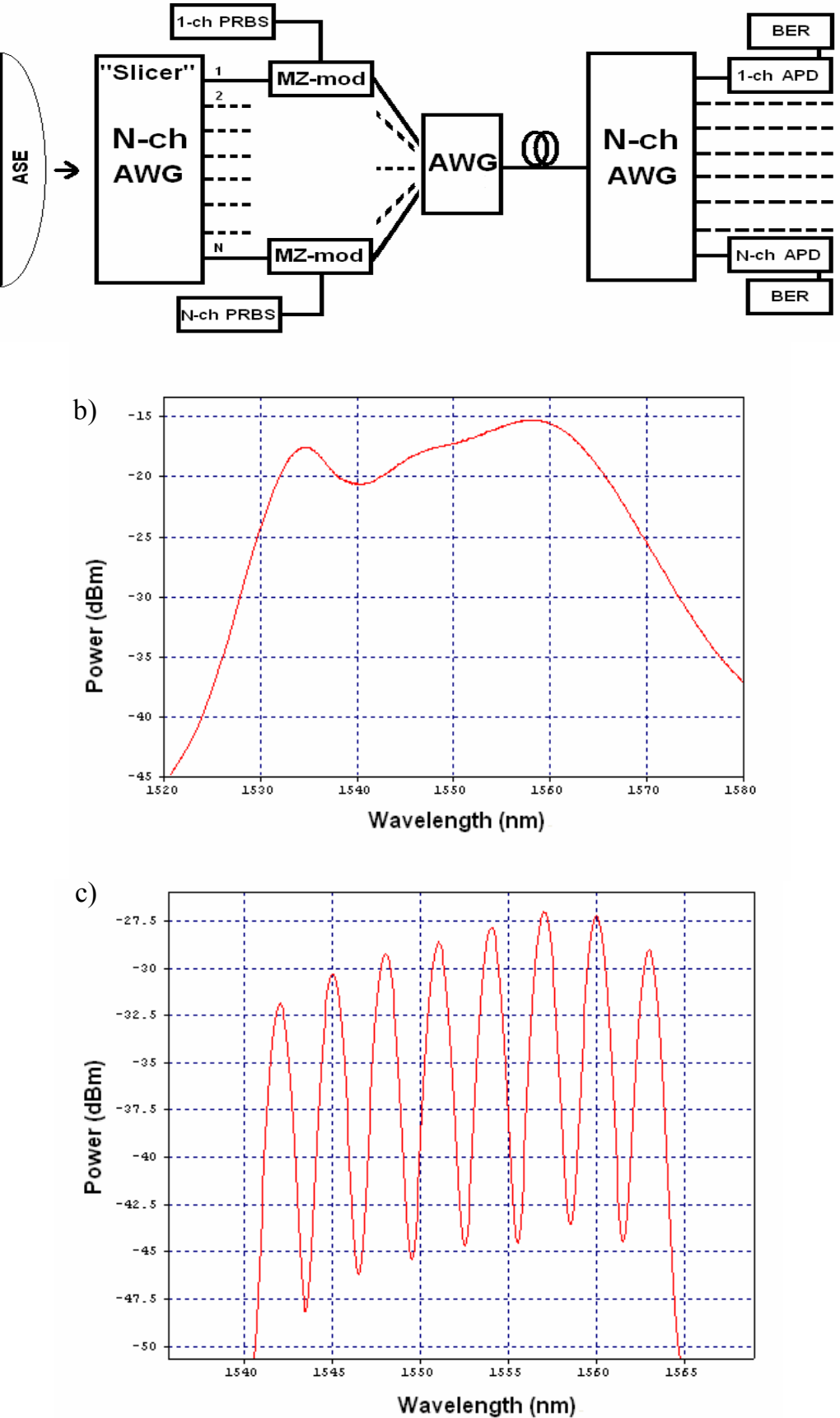

Fig. 3. Spectrum sliced system: physical topology $(a)$; ASE broadband spectrum before slicing $(b)$; after filtering and modulation $(c)$.

In our proposed Hybrid TDM/WDM-PON system we use a multiwavelength optical source of the kind to generate multiple OLT (Optical Line Terminal) channels in a single fiber (the downstream channels). This conception (illustrated in Fig. $3 a$ ) is similar to the use of a broadband noise source and spectral slicing technique [8,9]. According to this technique, a broadband source of ASE (Amplified Spontaneous Emission) shown in Fig. $3 b$ is ,sliced” with arrayed wave- 
guide grating by portions, separating some channels (Fig. 3c). All these channels are externally modulated and composed together using the second AWG. In contrast, with spectral broadband source channel slicing, the FWM-generated channels do not need slicing, because they have a good enough interchannel isolation (at least $20 \mathrm{~dB}$ ) and a narrow spectrum minimizing the dispersion penalty. In such a slicing the spectral width per channel depends on the AWG parameters. To achieve enough power after slicing the mentioned penalty this width should be at least $0.8 \mathrm{~nm}$, while in the FWM case it could be at a level of $20 \mathrm{MHz}$ for the carrier or $1 \mathrm{GHz}$ after pre-SBS modulation to fight the dispersion. After the FWM generation of channels using spectral slicing technique they are to be separated with a precise step and then modulated. By external modulators each FWM carrier frequency is turned into an information channel with a bit rate of $10 \mathrm{Gbit} / \mathrm{s}$. The total number of such channels is 8 per fiber in our case, but can potentially be greater as it depends on numerous factors (e.g. the output power of pump lasers, the parameters of nonlinear media used to stimulate FWM, the necessary precision of channel parameters, etc.). Under certain conditions such channels can easily be aligned to a specific wavelength grid, e.g. a DWDM grid [10], so that the standard components can be employed for channel multiplexing/demultiplexing, which is one more advantage of an FWM-generated multiwavelength signal source as compared with laser arrays.

In our system we used the wavelengths that correspond to 8 DWDM channels in the 193-193.7 THz frequency range with a $100 \mathrm{GHz}$ channel spacing. For this purpose we had two $25 \mathrm{dBm}$ pump lasers at 193.3 and $193.4 \mathrm{THz}$ and a $1.11 \mathrm{~km}$ long highly nonlinear fiber (HNLF) with the zero dispersion frequency at 193.35 THz (half-way between the two pump lasers). To suppress the Brillouin scattering the $1 \mathrm{GHz}$ phase modulation was applied to each pump laser.

In the proposed system the upstream channel was made using an O-band (1260-1360 nm) TDM common channel, since the upstream physical realization needs separate fibers and splitters.

\section{EXPERIMENTAL SETUP}

Our study was based on the evaluation of BER (Bit Error Rate) parameter and the power budgets of the downstream and upstream channels using the OptSim simulation software. The computations of both channels were performed separately, in different simulation modes of the software.

As was mentioned above, we used two pump lasers and a $1.11 \mathrm{~km}$ HNL fiber with the attenuation of $0.9 \mathrm{~dB} / \mathrm{km}, D=-0.05 \mathrm{ps} / \mathrm{nm} \cdot \mathrm{km}$ and $\beta_{2}=$ $0.06214 \mathrm{ps}^{2} / \mathrm{nm}$ (for $\lambda=1550 \mathrm{~nm}$ ), and the core effective area of $11.7 \cdot 10^{-12} \mathrm{~m}^{2}$. Figure 4 shows the block diagram of the FWM generating module. The side harmonics seen in Fig. 2 appear due to a cascading nature of the FWM phenomenon. They must be eliminated before the modulation of each channel to reduce the noise level of the side channels. For this purpose an AWG demultiplexer was used, which was centered at $193.35 \mathrm{THz}$ with $100 \mathrm{GHz}$ channel separation and FWHM (Full Width at Half Maximum) value of $50 \mathrm{GHz}$ for each channel. One of the main goals in our experiment was to achieve a low power non-uniformity of channels (8-channels in our case) in the multiwavelength signal, balancing between the output power and the HNLF length. 


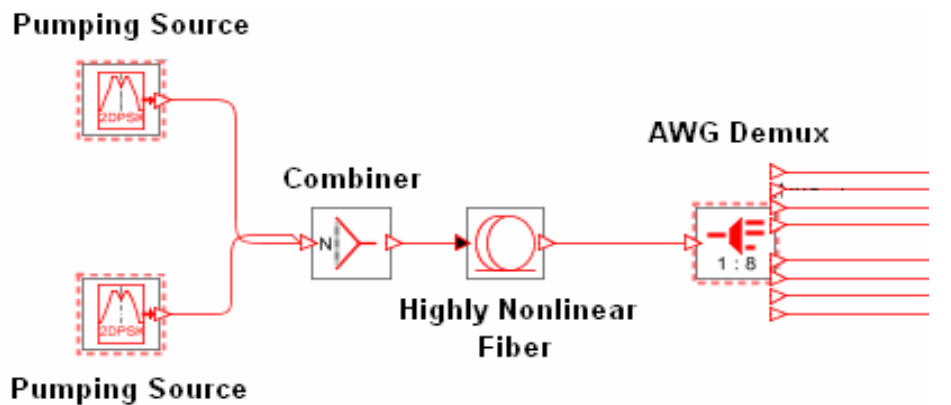

Fig. 4. Block diagram of the FWM generating module. Table 1).

The maximum difference in power between two channels was $4.1 \mathrm{~dB}$ (see

All the calculations were done for the side channels (1 and 8), because they had the lowest output power, i.e. they were the worst case channels. For all the results relating to other channels the BER value was $10^{2}$ times better than for the worst $1^{\text {st }}$ and $8^{\text {th }}$ channels. The calculations for the best channels ( 3 and 6$)$ were also performed, which showed a BER decrease by at least a factor of $10^{2}$.

Channel power distribution

Table 1

\begin{tabular}{|l|c|c|c|c|c|c|c|c|}
\hline Channel № & 1 & 2 & 3 & 4 & 5 & 6 & 7 & 8 \\
\hline Power, $\mathrm{dBm}$ & 10.1 & 12.9 & 14.2 & 11.3 & 11.3 & 14.2 & 12.9 & 10.1 \\
\hline
\end{tabular}

In the power margin calculations the power level non-uniformity should be taken into account also for the situation where the losses are small and the received power level can overtake the receiver's overload level. To solve this problem a flattering filter can be used, however it adds extra attenuation and dispersion.

Each demultiplexed optical signal was modulated with a Mach-Zehnder (MZ) external modulator (extinction ratio $14 \mathrm{~dB}$ and internal losses $4 \mathrm{~dB}$ ). The logical data source generates a $10^{23}-1$ pseudorandom bit sequence at $10 \mathrm{Gbit} / \mathrm{s}$ and is provided with a non-return-to-zero (NRZ) coder. This is a standard solution that was chosen due to its simplicity and cost efficiency of realization. All components are shown in Fig. 5a. The AWG multiplexer has the same parameters as the demultiplexer with the insertion loss (IL) of $2.5 \mathrm{~dB}$ per channel and the polarization-dependent loss (PDL) of $0.2 \mathrm{~dB}$. All the channels after modulation were inserted into a $20 \mathrm{~km}$ long G. 652 fiber, with an effective core area of $81 \cdot 10^{-12} \mathrm{~m}^{2}$; other parameters were: attenuation $\alpha=0.2 \mathrm{~dB} / \mathrm{km}(1550 \mathrm{~nm})$, dispersion $D=$ $16 \mathrm{ps} / \mathrm{nm} \cdot \mathrm{km}$, dispersion slope $D_{s l}=0.07 \mathrm{ps} / \mathrm{nm}^{2} \cdot \mathrm{km}$, dispersion parameter $\beta_{2}=$ $-20.4 \mathrm{ps}^{2} / \mathrm{nm}$, and nonlinear refractive coefficient $n_{k}=2.5 \cdot 10^{-20} \mathrm{~cm} / \mathrm{W}$ at the reference wavelength $\lambda=1550 \mathrm{~nm}$.

The distance was chosen with regard to the ITU-T G.984 standard (GPON). It should be noted, however, that in Europe most OLT-ONT distances usually do not exceed 2-3 km [2]. According to the standard [1] a $20 \mathrm{~km}$ distance could be achieved only in the rural areas with people concentration at small distant places where it would be inefficient to install an ONT in every small village [11]. Another 
reason for such a distance and TDM/WDM convergence is the decrease in power consumption [1]. At the use of much higher bandwidths, a dramatic increase was observed in the power consumed at the central office. The increase in distances and better utilization of achievable fiber bandwidth would result in decreasing the ONT number and power consumption.

As the receiver, an APD (Avalanche Photodiode) with sensitivity $-24 \mathrm{dBm}$ for BER $=1 \cdot 10^{-12}$ was chosen. It is impossible to add the FEC (Forward Error Correction) in this mode of OptSim, therefore currently the BER calculations for the Reed-Solomone $(255,239)$ code are only applied to the upstream power budget.

a)

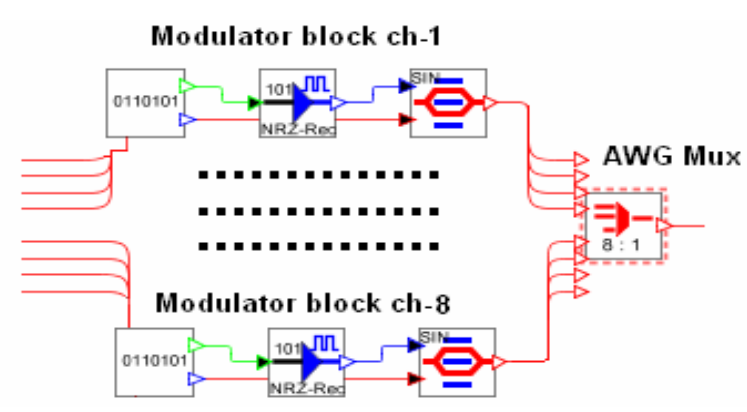

b)

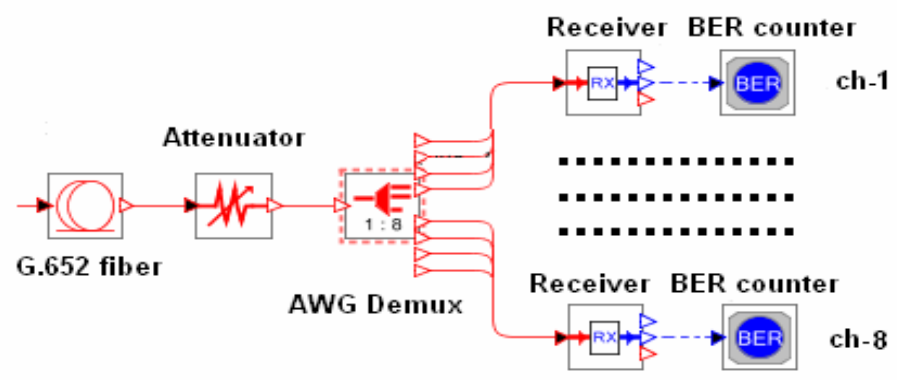

Fig. 5. Block diagrams: $a$ ) modulation unit $b$ ) receiver side.

The upstream channel is common for all the downstream channel groups (see Fig. 1). The upstream passive cable plant consists of 2 PLC (Planar Lightwave Circuit) splitters with the splitting ratio $1 \times 8$ (at the place of downstream $1 \times 8 \mathrm{AWG}$ Demux) and $1 \times 16$, with insertion losses $9.5 \mathrm{~dB}$ and $13.2 \mathrm{~dB}$, respectively, and PDL of $0.2 \mathrm{~dB}$. To compensate for high insertion loss of splitters, a SOA (Semiconductor Optical Amplifier) was used. Another reason for choosing SOA was its ability to work in the O-Band where the dispersion level is minimal. The laser output power level of $2 \mathrm{dBm}$ becomes $14.2 \mathrm{dBm}$ after SOA. However, SOA adds extra frequency chirp and noise, which decrease the signal-to-noise ratio and increase the inter-symbol interference (see Fig. 6). No EDFA (Erbium Doped Fiber Amplifier) with the minimum noise and absence of chirp could be used because it can work only in the C- and L-bands, whereas our physical and logical topologies do not allow using them. The receiving side (with the receiver sensitivity for O-band of $-22.8 \mathrm{dBm}$ ) was chosen in the manner similar to that of downstream realization. The sensitivity with $\operatorname{RS}(255,239)$ FEC is improved to -25.4 , with the coding gain of $2.6 \mathrm{~dB}$. 

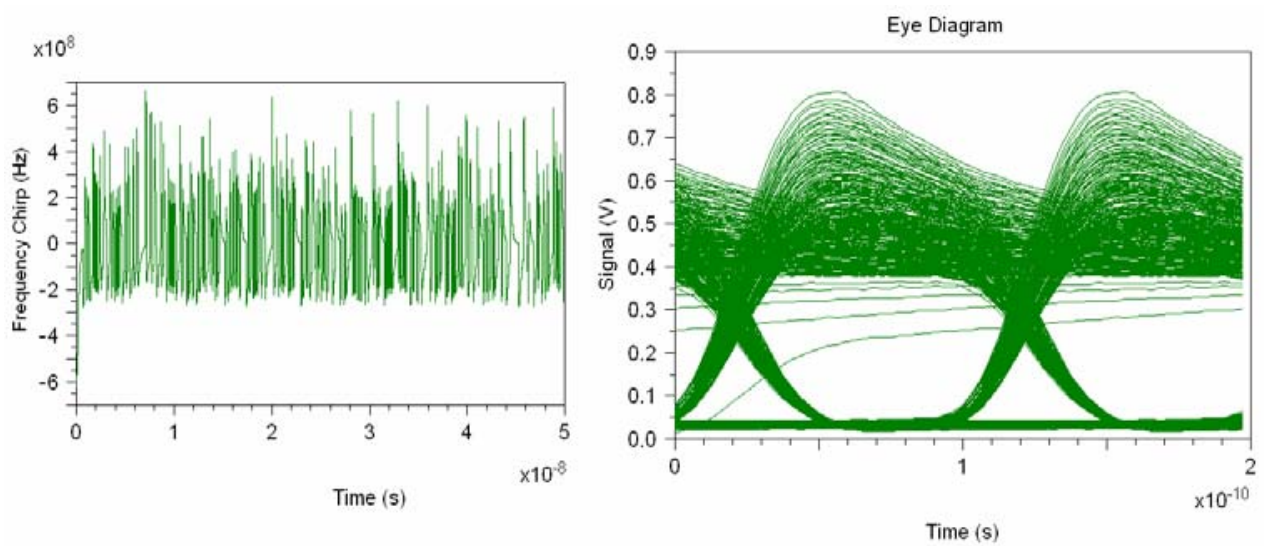

Fig. 6. Time dependence of $a$ ) frequency chirp;

b) pulse broadening and ISI (intersymbol interference).

\section{RESULTS AND DISCUSSION}

In our study we have evaluated the BER dependence of the inserted attenuation (see Fig. 7). The shown BER includes the losses of splices, connectors, and a splitter (not included in the simulation due to various possible arrangements of components) and the power margin. Figure 7 shows the diagrams for the worst (Fig. 7a) and the best (Fig. 7b) channels. The purpose was to achieve that the maximum possible inserted attenuation does not exceed the BER value of $10^{-10}$. For the final margin calculations we have chosen the $1^{\text {st }}$ channel (with the minimum power level of $10.1 \mathrm{dBm}$ ). The power margin level for downstream simulation analysis was found to be $4.3 \mathrm{~dB}$. The splitting ratio after AWG Demux was $1 \times 16$ (insertion loss $13.2 \mathrm{~dB}$ with fusion spliced connections). This margin is enough for losses due to equipment aging and degradation of connections resulting from improper installation but not enough to raise the splitting ratio (for this FEC with the coding gain the margin of $\geq 3-4 \mathrm{~dB}$ should be used).

a)

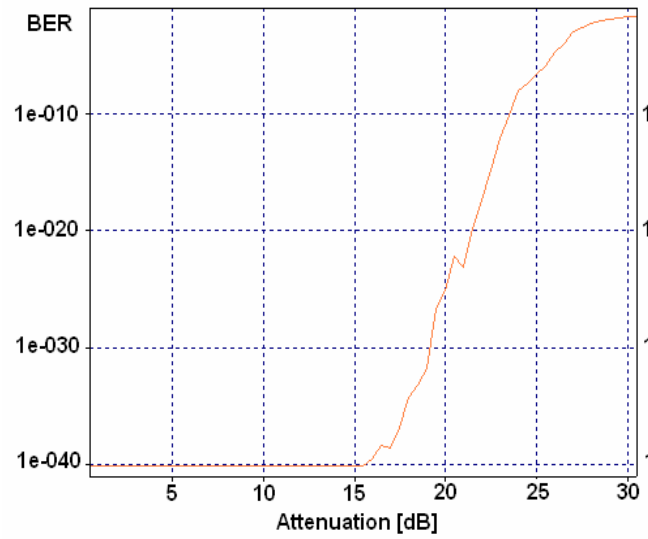

b)

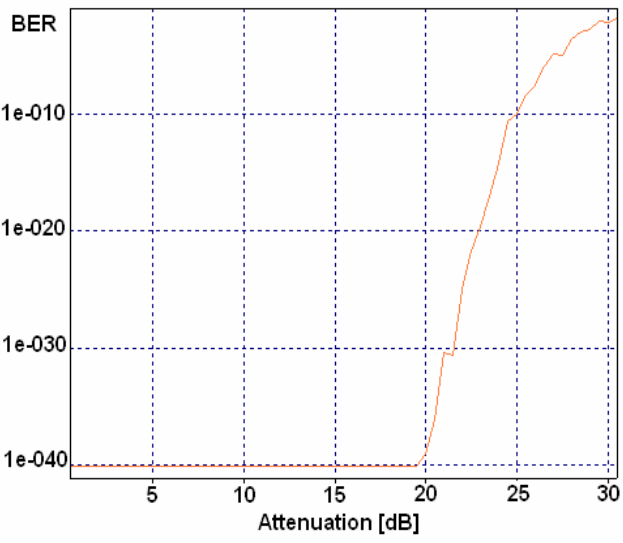

Fig. 7. BER dependence on the inserted attenuation: $a) 1^{\text {st }}$ channel; b) $3^{\text {rd }}$ channel.

The upstream power margin is $2 \mathrm{~dB}$ without FEC and $6.2 \mathrm{~dB}$ with it (as one can see in Table 2, the coding gain in the ISI presence is better). Figure 8 shows the 
BER dependence of inserted attenuation (the methodology is the same as in the analysis of downstream channel). Splitting ratios are $1 \times 8$ and $1 \times 16$ with $\mathrm{IL}=9.5$ and $13.2 \mathrm{~dB}, \mathrm{PDL}=0.2 \mathrm{~dB}$. The only difference is in the attenuation presentation. In the downstream power margin calculation the attenuation is with the positive sign, while in the upstream analysis - with the negative sign. A $2 \mathrm{~dB}$ power margin is not enough - neither for stable system's exploitation nor for increasing the splitting ratio. The use of FEC in the upstream channel is obvious; we however could not raise the splitting ratio.

Power budget in the downstream and upstream calculations

Table 2

\begin{tabular}{|l|c|c|}
\hline & Downstream & Upstream \\
\hline Output power, dBm & 10.1 & 14.2 (after SOA) \\
\hline MZ-modulator IL, dB & 4 & \\
\hline AWG-Mux IL, dB & 2.5 & \\
\hline Fiber loss, dB/km & 0.2 & 0.3 \\
\hline Distance, $\mathrm{km}$ & 20 & 20 \\
\hline Total fiber span loss, dB & 4 & 6 \\
\hline AWG-Demux IL, dB & 2.5 & \\
\hline $1 \times 8$ Splitter IL, dB & & 9.5 \\
\hline $1 \times 16$ Splitter IL, dB & 13.2 & 13.2 \\
\hline Splice loss, dB & 0.7 & 0.6 \\
\hline Connector loss, dB & 1.2 & 0.6 \\
\hline PDL loss, dB & 1 & 0.4 \\
\hline Dispersion loss, dB & 0.5 & 0.5 \\
\hline Receiver sensitivity, BER $=1 \cdot 10^{-12}, \mathrm{dBm}$ & -24 & -22.8 \\
\hline Receiver sensitivity (FEC), BER $=1 \cdot 10^{-12}, \mathrm{dBm}$ & & -25.4 \\
\hline Received signal, BER $=1 \cdot 10^{-12}, \mathrm{dBm}$ & -23.8 & -19.8 \\
\hline Received signal (FEC) BER $=1 \cdot 10^{-12}, \mathrm{dBm}$ & & -22.8 \\
\hline Theoretical margin, dB & 4.5 & 6.2 \\
\hline Theoretical margin $(\mathrm{FEC}), \mathrm{dB}$ & & 8.8 \\
\hline Simulation margin, dB & & 2 \\
\hline Simulation margin $($ with the $\mathrm{use}$ of FEC), dB & & 6.2 \\
\hline
\end{tabular}

Table 2 illustrates ,classical” calculations of the power budget (as is usually done in engineering applications [11, 12]). In addition to all insertion losses it includes the PDL values for the arrayed waveguide grating (AWG) with the dispersion penalty of $0.5 \mathrm{~dB}$. For the upstream channel the decrease in OSNR (Optical Signal-to-Noise Ratio) made by SOA was not included in the calculations. In Table 2 they are called ,Theoretical Margin”.

Comparison with simulation (Simulation Margin) has shown a minor spread of the results for the downstream channel $(0.2 \mathrm{~dB})$ and a huge mismatch for the upstream channel $(4.2 \mathrm{~dB})$. This means that the theoretical calculation for this type of system should be complemented by the chirp factor, taking also into account the OSNR decrease due to extra noise in SOA. For a system of the type it is equal to 
$4 \mathrm{~dB}$, however in the general case it can be evaluated only approximately. It should also be mentioned that in engineering calculations the nonlinear effect penalty is ignored [12].

a)

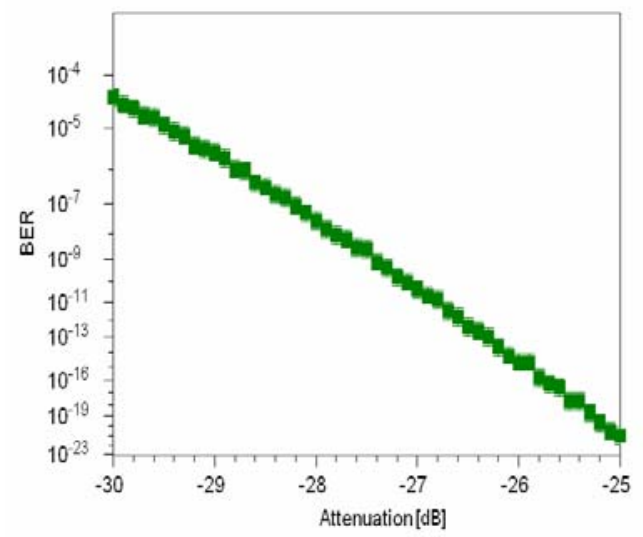

b)

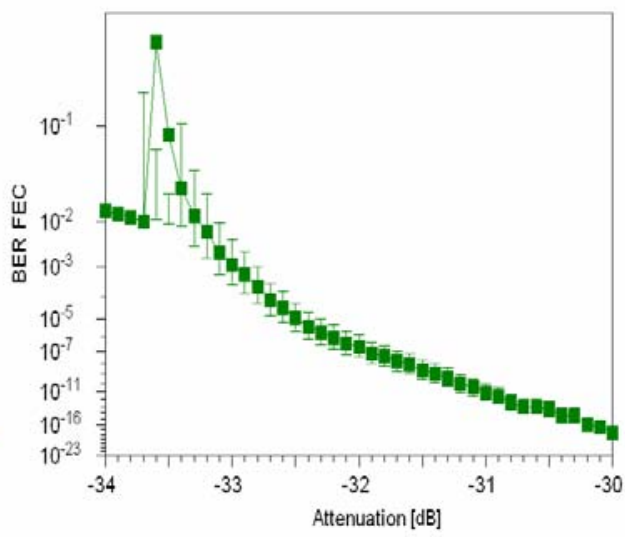

Fig. 8. BER dependence on the inserted attenuation $a$ ) without FEC; $b$ ) with FEC.

Simulation results have shown increase in the coding gain of FEC in the presence of high ISI. The theoretical coding gain of FEC $(2.2 \mathrm{~dB})$ was measured with the help of a receiver sensitivity test when only the transmitter, variable attenuator and receiver are in sight and when there could be ISI caused by dispersion and frequency chirp.

Due to zero chirp of the MZ-modulator and its stable noise characteristics the theoretical coding gain of $2.2 \mathrm{~dB}$ can be used in downstream channel calculations.

\section{CONCLUSIONS}

The research on the performance of the proposed Hybrid TDM/WDM PON using a nonlinear four-wave mixing for the generation of optical carrier signals has proved its feasibility in real life scenarios. The system for 128 users has a $8-\lambda$ downstream channel (with the splitting ratio $1 \times 16$ for each $\lambda$ ) and an upstream channel using SOA in the O-band. The simulation has also shown ways of the system's expansion and its possible limitations.

The main conclusions are therefore as follows.

- When optimizing the 8-channel system to the ITU-T wavelength grid, the least output power non-uniformity is $4.1 \mathrm{~dB}$. All the calculations afterwards have been made for the worst channel case.

- The downstream channels have power margins enough for safe and reliable system operation (at $4.3 \mathrm{~dB}$ the spread of $0.2 \mathrm{~dB}$ between the simulation data and the engineering budget calculation is negligible). The FEC coding gain of $2 \mathrm{~dB}$ could be used for the downstream power margin in the calculations for engineering applications. 
- The upstream channel reaches the necessary margin (see Table 2) only with the use of FEC coding $(6.2 \mathrm{~dB})$. The $2 \mathrm{~dB}$ margin (without FEC) is not enough for the stable system operation.

- The simulation has shown a huge discrepancy $(4.2 \mathrm{~dB})$ between the simulation and theoretical results for the upstream power margin due to frequency chirp and noise in SOA, which should be taken into account in field applications.

- The downstream scenario does not have enough margin for splitting ratio rise by the factor of 2 (from $8-\lambda$ to $16-\lambda$ configuration) since for this some extra $6 \mathrm{~dB}$ would be needed. The upstream scenario also does not allow such a rise in the splitting ratio but has however enough power margin for installation penalties and comfortable operation.

The future upgrade is only possible using WGR (Wavelength Grating Router) or other scenarios of the upstream realization (possibly, in the C- and Lbands).

\section{REFERENCES}

1. Hutchenson, L. (2008). FTTx: Current status and the future. IEEE Communication Magazine, 46, 90 - 95.

2. Prat, J. (2008). Next-Generation FTTH Passive Optical Networks. Springer Science+Business Media (USA).

3. Effenberger, F.J., Mukai, H., Park, S., \& Pfeiffer, T. (2009). Next-generation PON. Part 2: Candidate systems for next-generation PON. IEEE Communications Magazine, 47, 50-57.

4. Arismar Cerqueira, S. (Jr.), Chavez Boggio, J.M., Rieznik, A.A., Fragnito, H.L., Hernandez-Figueroa, H.E., \& Knight, J.C. (2008). Highly efficient generation of broadband cascaded four-wave mixing products. Opt. Express, 16, 2816-2828.

5. Arismar Cerqueira, S. (Jr.), Marconi, J.D., Hernandez-Figueroa, H.E., \& Fragnito, H.L. (2009). Broadband cascaded four-wave mixing by using a three-pump technique in optical fibers. Optics Communications, 282, 4436-4439.

6. Arismar Cerqueira, S. (Jr.), Chavez Boggio, J.M., Hernandez-Figueroa, H.E., Fragnito, H.L., \& Knight, J.C. (2007). Highly efficient generation of cascaded Four-Wave Mixing products in a Hybrid Photonic Crystal Fiber. 33rd European Conf. on Optical Communications - ECOC 2007, 16-20.

7. Arismar Cerqueira S. (Jr.), Marconi, J.D., Gabrielli, L.H., Rieznik, A.A., HernandezFigueroa, H.E., Fragnito, H.L., \& Knight, J.C. (2008). Multi-wavelength source at ITU-T grid based on ultraflattened dispersion photonic crystal fibers. International Journal of Optics, June.

8. L̦ašuks, I., Ozoliņš, O., Ščemel̦evs, A. (2009). Investigation of spectrum-sliced WDM system (2008). Electronics and Electrical Eng-g, ELECTRONICS'2008, 85(5), 45-48.

9. Lašuks, I. (2009). Investigation of colorless WDM-PON using a broadband ASEsource. Electronics and Electrical Eng-g, ELECTRONICS'2009, 94(6), 43-46.

10. Ščemel̦evs, A., \& Poriņš, J. (2009). BER performance of a lumped single-pump fiber optical parametric amplifier in a 10 Gbits 4-channel S-band DWDM System. Electronics and Electrical Engineering, ELECTRONICS'2009, 93(5), 11-14.

11. Chinlon, L. (2006). Broadband Optical Access Networks and Fiber-to-the-Home. Wiley \& Sons (UK).

12. Chomycz, B. (2009). Planning Fiber Optic Networks. USA: The McGraw-Hill Companies, Inc. 


\title{
HIBRİDĀ TDM/WDM-PON SISTĒMA AR DAUDZVIḶN̦U OPTISKO SIGNĀLU ĢENERATORU, KAS IZMANTO ČETRVIḶN̦U SAJAUKŠANĀS EFEKTU
}

\author{
I. Ļašuks, A. Ščemel̦evs, Ģ. Ivanovs
}

Kopsavilkums

Šajā publikācijā iepazīstina ar jaunu FTTx metodi, kas balstās uz četru viḷnu mijedarbes izmantošanu. Izmantojot BER (Bit Error Rate - Bitu Kḷūdu Intensitāte) un optiskās jaudas budžeta aprēķinus, mēs esam novērtējuši hibrīdo TDM/WDM sistēmu ar četru viḷnu mijedarbes generētiem optiskiem signāliem. Pētijuma rezultāti parāda, ka, izmantojot FEC (Forward Error Correction Turpvērstā Kḷūdu Labošana), ir iespējams panākt jaudas rezervi, kas nepieciešama sistēmas stabilai darbībai reālos apstākḷlos. Šì sistēma spēj maksimāli nodrošināt 128 lietotājus ar vairāku simtu Mbit/s piekļuves ātrumu uz vienu lietotāju, izmantojot eksistējošo pasīvo optisko tīklu infrastruktūru ar nelielām izmaiņām.

30.08.2010. 